August - 2004

\title{
Something Old - Something New
}

\author{
Terry Anderson PhD \\ Canada Research Chair in Distance Education \\ and incoming Editor, International Review of Research in Open and Distance Learning
}

This issue of IRRODL marks a significant evolution in the development of your open access, peer-reviewed, international, online learning journal. Changes include new enhancements to our delivery model and some changes in the Journal's editorial personnel. However, rest assured that IRRODL remains committed to providing our distance education research community readers with a high quality, open access e-journal.

This issue marks the first change in editorship of IRRODL since its founding four years ago by Peter Cookson. Although I have taken over as Editor and Publisher, I am happy that Peter will continue supporting IRRODL as a member of our editorial board. I want to thank Peter for his considerable contribution in setting the vision and policy that has defined IRRODL, and for successfully leading the editorial and administrative activities that have created what is likely the mostly widely read, peer reviewed, distance education journal in the world.

This issue also marks the first in our new "continuous batch" publication model. Beginning this issue, IRRODL will be published when we have enough quality, peer reviewed main and research note articles, book reviews, and technical notes to compile an issue. This publication model allows for more issues, of reasonable size, to be published than the twice a year publication practice of the past. In addition, the new model will reduce the delay between submission, editing, and publication. Continuous batch production also allows us to retain the coherency of a complete issue, and yet also reduces an overabundant email "alerts" typical of publications that publish single articles as they are accepted. We anticipate publishing between three to five issues per year, but the exact number will depend on the number of quality submissions and our peer reviewers' availability and production capacity.

We are also striving to increase the numbers of special issues, specifically those that focus on geographic regions (we expect to have an Australian special issue early next year) or on topical issues related to significant happenings in open and distance learning. New guidelines related to process for editing a special issue are available from the IRRODL website.

Finally, although we continue to support full and open access to IRRODL, we now have paid subscribers to IRRODL. The reason why we have opted to solicit 'paid subscribers' is because the Canadian Social Sciences and Humanities Research Council has a program designed to support scholarly journals published in Canada. To be eligible to apply for this funding, however, IRRODL needs at least 200 'paid subscribers' per year. Our current 7050 unpaid subscribers were deemed insufficient to demonstrate community demand! Thanks to the 280 distance educators who feel strongly enough about the value of Open Access and this journal, to donate a $\$ 10.00$ subscription fee, we met this arbitrary criteria for this year and have submitted our grant 
application - though we are not at all certain how successful that application will be. The voluntary subscriptions also demonstrate our capacity to expand support for IRRODL beyond that generously provided by Athabasca University. However, we do not intend to compromise on policies or on practices that might restrict access to IRRODL. Indeed, we are very concerned that most other major distance education journals are now commercially published or published only in print format - thus restricting access to all and especially to those in developing countries. We do not intend to let this happen to IRRODL.

I have talked about a lot "what's new," but perhaps I should talk about "what's old." The structure of each IRRODL issue will continue to consist of feature articles in the Main Section. Each of these articles makes a significant advance to the field and adds new ideas to the literature. Our Research Note articles, on the other hand, generally confirm previous findings and thus add depth and breadth to existing literature. Both sections are rigorously peer reviewed, and both sections add value to our readership and our discipline. Each issue will also feature 1-3 book reviews.

Finally each issue will contain a Technical Notes feature. Technical Notes has proven to be one of IRRODL's most popular downloads, offering readers practical reviews and evaluations of new and emerging educational technologies relevant to open and distance learning. Most of us feel somewhat intimidated by the rush of new products continuously being brought to market. These reviews and commentaries by Jon Baggaley, his colleagues and his students in Athabasca University's Master of Distance Education program provide a commercial free commentary that can be searched from the IRRODL site whenever we feel technically challenged.

We also continue to insist upon distribution of high quality product. This practice means that we have a fairly high rejection rate as we sift through submissions to find and develop those manuscripts that make significant contributions and warrant the time of our busy reviewers and readers. We also continue the practice of using top-rated academics and practicing researchers to peer review our Main and Research Note content. The anticipated increase in number of issues and need to provide review experiences for new academics has created a need for new members of our editorial review team. If you would like to serve as a student or a regular editor for IRRODL articles, you are invited to send a copy of your résumé and an email detailing your experience, expertise, and interest to myself.

\section{Highlights of Volume 5, Number 2}

\section{Main Section: Adding to the literature}

Blended Learning and Sense of Community - Fred Rovai and Hope Jordan present a study that examines the sense of community in blended learning environments. At least in the North American context, and likely globally, distance education techniques and tools are rapidly being adopted to enhance and allow time and place shifting for campus-based learners in what is often referred to as blended learning. Although considerable prior research has examined the development of community in distance education, little work has been done examining community formation in higher education blended learning environments. Rovai and Jordan stretch the boundaries on current literature on this topic. To add depth and breadth to this timely topic, we invited the reviewers of this paper to provide a commentary. Dan Eastmond of Western Governors University kindly stepped forward to write a commentary. In turn, the authors have also provided their response to Dr Eastmond's commentary, on what I will editorialize as truly interesting research into blended learning environments how students create sense of community. 
. Peek Into the Life of Online Learning Discussion Forums - In this article, New Zealand's Mary Allen presents an evaluation tool to graphically display social communication among participants in asynchronous discussion groups. This approach adds an easy to use graphic representation of online dialogue that plays such an important role in much online education models in use today. Much research has focused on extracting meaning, insights, and mechanisms to improve learning from computer conferencing transcripts. Unfortunately, much of this work is very time intensive. The development of visualization tools that highlight the extent and type of interaction may well develop into easy-to-use and informative tools that make a difference in practice.

Washington Online Virtual Campus: Infusing Culture in Dispersed Web-based Higher Education - Shalin Hai-Jew, a seasoned distance educator who is just completing her doctorate in Seattle, USA, examines cultural implications in organizing distance education consortiums. The cost of developing and maintaining distance education programs can be prohibitive for single institutions. Thus, there is considerable interest in consortiums to share financial expense and risk, and to leverage advantages of particular institutional skills and assets. Hai-Jew examines the implications of such a consortium and provides suggestions for developing a "common culture" that recognizes difference among different institutions, yet holds the consortium together enough to create and sustain an effective organization.

Interaction and Immediacy in Online Learning - Robert Woods and Jason Baker provide a theoretical contribution that first overviews and then critiques our perennial focus on interaction in distance education. By highlighting the notion of immediacy, they argue that it is not interaction itself that leads to learning, but rather the nature and affective components of that interaction. They provide a new learner-centered model of interaction that shows interaction relationships between a learner and their community, context, the instructor and content.

\section{Research Notes: Supporting the literature}

Faculty Opinions on Introducing e-Learning at the University of Bahrain - Muain Jamlan's paper offers readers the results of a internal study undertaken at the University of Bahrain designed to examine faculty's perceptions of e-Learning. Like other institutions of higher education the world round, the University of Bahrain is seeking to lay the foundation to support a coherent system to deliver campus-wide e-Learning initiatives. Clearly, designing such a comprehensive e-learning system entails that the necessary resource and human infrastructure are in place to make it happen. Jamlan offers readers his perspectives on the challenges faced at his university, and his institutions' attempts at developing a workable and cost effective plan to incorporate e-learning into mainline campus activities.

Open University and Distance Education Coordination: Strategies to Consolidate Distance Education at the National Autonomous University in Mexico - Citlalli Berruecos's paper describes how Mexico's flagship research university, UNAM, has consolidated its distance learning departments and expanded its e-Learning initiatives on that campus. It describes, in broad detail, the three initiatives used to achieve the institutions objectives. These deal with developing an open source Learning Management System (LMS); changing the administrative structure of the University to support consolidation; and the development of a high-tech center to ensure that UNAM has the technical infrastructure and human resource support system needed to sustain the effort. The paper also examines team structures typically used in corporate settings, the drivers of the change, and the importance of clearly defining goals across the institution. 
Distance Education and Case for Two Different Distance Education Courses - Christos Pierrakeas, Michalis Xenos, Christos Panagiotakopoulos, and Dimitris Vergidis examine and compare the causes of student drop out at Greece's Hellenic Open University in two fundamentally different courses: an undergraduate course in computer technology, and a graduate course in education. Like previous research, it reveals challenges faced by busy adults undertaking higher education studies for the first time (e.g., due to juggling family obligations and work commitments, students age 30 - 39 are more at risk for dropping out than other student populations; students who have a graduate degree tend to be less inclined to drop out, etc.). It also illustrates how learners, throughout the world, provide very similar reasons for dropout, and thus give us insights into ways to alter our program structures to accommodate learner constraints.

\section{Departments}

Two book reviews are included in this issue. Insung Jung reviews The Advancing Online Learning in Asia, co-edited by Murphy, Shin and Zhang, of the Open University of Hong Kong. The second, Distance Education and Distributed Learning, edited by Vrasidas and Glass, is reviewed by India's Ramesh Sharma.

Finally, we wrap up this issue with the latest installment of Dr. Jon Baggaley's Technical Notes, one of IRRODL's most popular downloads.

To finish up, I'd like to thank IRRODL's readers for their support of this open access e-journal. We feel it makes an important contribution to the field of distance and open education research, theory, and practice. I'm glad you are here to see us grow and expand in new directions in our fifth year of publication. I am also proud to be the new editor of IRRODL. It has truly been an eye-opener to witness all the work, by IRRODL's many contributors, in bringing each issue to your screen.

Terry Anderson

August 14, 2004

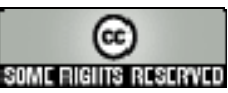

